\title{
Emoções e sentimentos: considerações sobre sua apropriação na abordagem dos dilemas morais
}

\author{
Emotions and Feelings: Considerations on their \\ Appropriation in Addressing Moral Dilemmas
}

\author{
${ }^{*}$ Ricardo Bins di Napoli \\ ** Lauren de Lacerda Nunes
}

\begin{abstract}
Resumo: Este trabalho objetiva apresentar razões para a apropriação das emoções e sentimentos na abordagem dos dilemas morais. Isso será feito em três etapas. Primeiramente, ele partirá da análise de Williams em seu artigo Ethical consistency, onde ele dá um primeiro passo no sentido de defender o papel de emoções como remorso e arrependimento, além da introdução da ideia do "resquício emocional" em dilemas morais, com a finalidade de mostrar a importância deste argumento para nossa perspectiva. Em um segundo momento, se reconstruirá a análise de Statman, porque sua sistematização do "argumento dos sentimentos" em favor dos dilemas morais mostrou que não. Em um terceiro momento, a análise se concentrará no artigo Sentiment and Value, de D'arms e Jacobson, que aborda questões prementes acerca da possibilidade de um sentimentalismo moral de base racional. Por fim, se tais abordagens o apelo aos "fatos morais" levam a uma possível justificação dos sentimentos de arrependimento, culpa ou remorso experienciados pelo agente em dilemas morais, então conclui-se que estes não devem ser desconsiderados em uma abordagem mais intuitiva e ampla da questão.
\end{abstract}

Palavras-chave: Dilemas Morais. Sentimentos Morais. Emoções. Culpa. Arrependimento.

* Professor associado no Departamento de Filosofia da Universidade Federal de Santa Maria. Academic Visitor (2012) na Universidade de Oxford, departamento de Filosofia. <ricardo. bnapoli@gmail.com>.

** Professora assistente na Universidade Federal do Pampa (UNIPAMPA-RS), campus São Borja. Doutoranda pelo Programa de Pós-Graduação da Universidade Federal de Santa Maria (2011) e Academic Visitor (2014) na Universidade de Oxford, Reino Unido, no Oxford Uehiro Centre for Practical Ethics. <laurenlacerdanunes@gmail.com>. 


\begin{abstract}
This work aims at elucidate the reasons for appropriating the sentiments and emotions in the approach of moral dilemmas. Therefore, first it will start with an analysis of Williams in his article Ethical Consistency where the author approaches de role of the emotions such as remorse and regret, and also introduces the idea of "moral remainder" in moral dilemmas. In a second moment, this work will be concentrated in the analysis of Statman in his article The debate over the so-called reality of moral dilemmas and his systematization of the "sentiments argument" in favor of moral dilemmas. In a third moment, the analysis will focus on the article Sentiment and Value, of D'arms and Jacobson which approaches important questions concerning the possibility of a moral sentimentalism with a rational basis. Finally, the focus will be in the question if in such approaches the appeal of "moral facts" could possibly justify the feelings of regret, guilty or remorse experienced by the agent in moral dilemmas, then these feelings cannot be disregarded in a more intuitive and broader approach of the issue.

Keywords: Moral Dilemmas. Moral Feelings. Emotions. Guilty. Regret.
\end{abstract}

\title{
1 Williams e a tese do resquício moral
}

W illiams (1965) foi um dos primeiros filósofos a considerar os dilemas morais através de um prisma mais "sentimental"1. O argumento de Williams (1965, p. 104) pode ser dividido em três partes: 1) Conflitos morais têm estrutura de conflitos de desejos; 2) Por isso, não são solúveis sem "resquício" emocional relativo ao dever não seguido; 3) Os sentimentos de remorso e arrependimento seriam indicativos de tal "resquício". De todas, a parte "3" do arugumento é sem dúvida a mais problemática de ser explicada, pelos motivos que se seguem.

Com relação a (1), Williams (1965, p. 104) afirma que é possível realizar uma comparação entre conflitos morais e conflitos de desejos, mas não entre os primeiros e conflitos de crenças. A explicação reside no fato de que conflitos morais apresentam a mesma estrutura de conflitos de desejos, que diferem dos conflitos de crenças. Em outras palavra, após a decisão tomada em um conflito moral, o dever que não puder ser cumprido "permanece" da mesma forma que o desejo não satisfeito em um conflito de desejos permaneceria. Justamente aí reside o ponto de Williams: o desejo não satisfeito e o dever não cumprido em situações de conflito preservam certa "força".

Com relação a (2), Williams (1965, p. 107) acrescenta mais algumas observações no que concerne à comparação entre conflitos morais e conflitos de desejos. Os primeiros compartilham com os segundos o

1 Os termos "emoção" e "sentimento" serão utilizados de forma indistinta no presente trabalho. 
aspecto de que uma vez tomada uma decisão pelo agente moral, ele não elimina necessariamente a outra alternativa de ação conflitante. Deste modo a que não for escolhida poderá persistir como uma espécie de "resquício". Esse pode (embora não sempre) receber uma expressão construtiva. Williams (1965, p. 107), por exemplo, defende a possibilidade de que nenhuma das "obrigações" (alternativas) em um conflito seja "eliminável", porque o agente não sentir-se-á livre para reestruturar seu pensamento moral a ponto de eliminar a alternativa não cumprida de seu universo facilmente.

A esse respeito, Williams afirmou que lhe parecia "impossível nos atermos a uma apresentação lógica que faça com que o conflito tenha como consequência necessária que um dos deveres deva ser totalmente rejeitado, no sentido de que nos convenceríamos de que ele não possuía verdadeiramente realidade" (1965, p. 121).

Por esse motivo, Williams (1965, p. 107) afirma em (3) que se o agente, em situação de conflito moral, finalmente escolher a qual obrigação cumprir, então se tem aberta a possibilidade para o sentimento de arrependimento. Sentimento este que será apropriado da mesma forma que é no conflito de desejos, pelo desejo que não pôde ser satisfeito. Evidentemente, no caso de um conflito moral, o sentimento terá uma conotação moral. Como foi mencionado anteriormente, esta seria a parte mais problemática do argumento de Williams (1965, p. 108), devido a uma afirmação que o autor realiza logo em seguida: tais estados mentais (de arrependimento e remorso), não dependem do fato de o agente estar convencido se agiu pelo melhor em um dilema moral ou não. Para Williams, tais sentimentos podem surgir quando o agente sente que não poderia ter agido melhor.

Considerando o sentimento de arrependimento, há possibilidade dele surgir em casos onde o agente sinceramente acredita que agiu pelo melhor. Para ilustrar, Williams (1965, p. 113) cita o caso das promessas. Um agente pode, por exemplo, sentir arrependimento por ter quebrado uma promessa com alguém, mesmo tendo feito isso como a melhor alternativa de que dispunha. Parece que o arrependimento, em tais circunstâncias, seria totalmente irracional. Entretanto, Williams (1965, p. 113) pondera que sentir arrependimento, nessa situação, pode ser um sinal indicador do fato de que o agente leva suas promessas a sério. Uma objeção a essa ideia, terá o ônus de lidar com essa suposta indicação de o agente ser alguém que leva suas promessas a sério.

Resumindo, se quis dizer que. as obrigações não escolhidas em conflitos morais permanecem para Williams (1965, p. 117) na forma de um resquício que é expresso pelo agente na forma do sentimento de arrependimento. Esse fenômeno não aconteceria em todos os conflitos 
morais, mas em apenas alguns deles. Ele poderia aparecer mesmo quando o agente tivesse certeza de ter agido pelo melhor, justamente porque, mesmo tendo feito isso, a obrigação que não fosse cumprida não perderia sua significância, permanecendo como um resquício.

Williams (1965, p. 121) reitera essas ideias no final de seu artigo ao afirmar que a decisão em situações de conflito é a opção por uma das obrigações, quaisquer critérios de decisão que se use. Mas que isso, de forma alguma, representa a reafirmação da obrigação que for escolhida seguida da negação implícita daquela que não foi. Essa colocação explica, porque um homem que tenha certeza que agiu pelo melhor, possa sentir o arrependimento ao qual Williams se refere. O agente poderá sempre pensar que poderia ter agido diferente, mesmo tendo consciência de ter agido pelo melhor. Sua decisão por uma das obrigações, não pode estar baseada no fato de que a outra obrigação em questão não possuía aplicação nenhuma. Este, conforme Williams (1965, p. 120), não deve ser o critério de sua escolha.

Como foi dito anteriormente, o argumento de Williams (1965) sobre o arrependimento e sua consequente conexão com um suposto "resquício" em conflitos morais é problemático. Philipa Foot, por exemplo, no artigo Moral Dilemmas Revisited (2002) afirma que Williams parece considerar os sentimentos "proposicionais" e, dessa forma, sentir arrependimento seria "como se alguma coisa, de alguma maneira má, tenha acontecido" (FOOT, 2002, p. 41). Entretanto, a autora pondera que, "disso não se segue que realmente tenha acontecido" (FOOT, 2002, p. 41). Em geral, Foot (2002, p. 41) argumenta que "é impossível passar da existência do sentimento para a verdade da proposição conceitualmente ligada a ele". E conclui que seria incorreto "pensar que a existência de sentimentos de arrependimento possa mostrar qualquer coisa sobre o resquício em casos de conflito moral" (FOOT, 2002, p. 41). Reside aí, o maior problema do argumento de Williams (1965), questão que Daniel Statman propõese a tratar em seu artigo The debate over the so called reality of moral dilemmas (1990).

\section{Statman: da realidade dos dilemas ao argumento dos sentimentos morais}

De acordo com Statman (1990, p. 191) a discussão dos dilemas morais comumente se concentra entre grupos de autores. O primeiro grupo é "contra" os dilemas, afirmando que tais dilemas são "aparentes". O segundo grupo, ao contrário, argumenta que os dilemas são genuínos e reais. No seu artigo Statman irá se concentrar neste segundo grupo, que se diz "a favor" dos dilemas. 
B. Williams (1965) argumenta que dos sentimentos morais mostram a genuinidade dos dilemas morais. Statman (1990, p. 191) admite que esse é um caminho problemático, mas tentará mostrar por que tal argumento, embora seja falho, exerce grande influência sobre aqueles que defendem os dilemas.

De acordo com Statman (1990, p. 193) o argumento dos sentimentos consiste:

Os sentimentos experienciados pelo agente (como a culpa) em um dilema provam que ele fez algo errado. Se esta prova estiver correta, mostra que mesmo quando um dever é superado por outro, ele ainda é real. Se não fosse, como explicar a existência desse resquício, dos sentimentos de culpa, da necessidade de se desculpar?

Via de regra, de acordo com Statman (1990, p. 193), a questão da realidade dos deveres não cumpridos ou superados é posta como idêntica à questão da realidade dos dilemas em geral. Pois, nos dilemas o agente está frente a dois ou mais deveres incompatíveis. Se um desses deveres for apenas aparente, então o dilema não é real, há apenas um dever, e consequentemente, nenhum dilema. Se, por outro lado, ambas as demandas são reais, é o caso de duas demandas incompatíveis e o dilema é real.

O interessante de argumentos neste estilo é que estes não podem provar a insolubilidade dos dilemas (tão requerida por determinados autores como Brink [1994] $]^{2}$ ), e sequer dependem de uma resposta positiva ou negativa a esse problema. Os sentimentos estarão presentes independentemente da existência de uma resposta correta ao dilema moral.

Dessa forma, o argumento dos sentimentos se mostra mais forte do que o argumento da insolubilidade (se os dilemas são insolúveis, então nenhum dever supera o outro, e logo, ambos são reais). Pois, se o argumento dos sentimentos for bem sucedido, prova a realidade dos dilemas mesmo quando forem solúveis, enquanto o argumento da insolubilidade prova a realidade apenas daqueles insolúveis. A objeção

\footnotetext{
2 Alguns autores - em sua maioria aqueles que recusam os conflitos morais - defendem que somente os conflitos insolúveis deveriam ser considerados "verdadeiros" conflitos. Entre eles, tem-se como um dos principais representantes Brink (1994, p. 220). Segundo ele, para que os conflitos sejam considerados realmente paradoxais, é defensável que se pense que as demandas morais neles envolvidas devam ser equipolentes - nenhuma deve ser mais forte do que a outra. $\mathrm{E}$ isso não diria respeito apenas ao ponto de vista epistemológico de que demandas morais que competem entre si pareceriam obrigatórias. Ao contrário do anteriormente exposto, Brink (1994, p. 220), esclarece que "Dilemas morais genuínos devem envolver equipolência metafísica: nenhuma demanda moral pode ser mais pesada do que a outra. Se assim for, dilemas morais devem invocar conflitos insolúveis de obrigações prima facie. Por isso, parece não haver nada de muito surpreendente sobre a existência de obrigações prima facie conflitantes [em conflitos solúveis] que [claramente] superam uma à outra. (BRINK, 1994, p. 218).
} 
mais utilizada contra o argumento dos sentimentos, entretanto, é bastante óbvia: onde há resposta certa, não há dilema, então, por que insistir ainda sobre esse ponto?

Para Statman (1990, p. 193) a insistência vale a pena, porque parece que o argumento dos sentimentos apresenta um apelo aos "fatos morais". Mas o que seriam tais "fatos morais"? E eles seriam capazes de sustentar uma visão de que mesmo os dilemas solúveis, sejam considerados genuínos?

Statman (1990, p. 203) afirma que se pode pensar situações nas quais, embora uma das opções do agente seja melhor (ou menos má) do que a outra, seria muito "artificial" negar o nome de dilema moral a elas. Ele, oferece um exemplo. Será que alguém poderia evitar uma guerra nuclear e salvar milhares de vidas inocentes sem causar danos morais à pessoa alguma? Para Statman só poderia fazer isso traindo, violando promessas, traindo familiares e amigos. Isso levaria a um dilema para o agente, pois salvar vidas não pode ser compatível moralmente com violar promessas e praticar traições contra confiança que as pessoas têm em nos outros.

Dificilmente se poderia negar ser este um caso de dilema moral. É também difícil negar que exista uma coisa certa ou melhor a se fazer, ou seja, evitar a guerra. Certamente, pode-se insistir que um dilema moral como este não tem resposta certa e que, portanto, o exemplo acima, e qualquer outro do tipo, não seriam dilemas morais. Mas embora não haja nada de inconsistente em tal posição, isso parece ad hoc e incorrer em petição de princípio, afirma Statman (1990, p. 203).

É importante dizer, contudo, que há um forte apelo intuitivo no tipo de exemplo mencionado acima. Existe, de fato, um momento no qual o agente sente-se profundamente angustiado pelas suas opções, e sabe que não poderá evitar trair, mentir, ou seja, cometer erros morais que irá certamente arrepender-se depois. Mas que no momento da decisão eram inevitáveis, mesmo a opção correta estando disponível e evidente. Este seria, pensa-se, o forte apelo dos "fatos morais" a que Statman (1990, p. 193) se refere. Por isso, devido a este apelo, ele prefere admitir a realidade de dilemas morais solúveis, bem como outros autores também o fazem, a exemplo de Marcus:

Dizer que uma das obrigações conflitantes foi apagada é o mesmo que dizer que sentir culpa ou remorso sobre ter falhado com aquela obrigação é errado. Dessa forma, é o mesmo que dizer que o agente acredita falsamente que é culpado, uma vez que sua obrigação foi invalidada e seus sentimentos são inapropriados. Mas isso não condiz com os fatos. Mesmo onde as prioridades são claras e superam-se, e mesmo quando o fardo da culpa é apropriadamente pequeno, explicações e desculpas são apropriadas. (MARCUS, 1980, p. 121-122) 
Dessa forma, Statman (1990, p. 196), a esta altura, resume o argumento dos sentimentos: certos sentimentos experienciados pelo agente em um dilema moral, especialmente os de culpa, provam a realidade do dever não cumprido e, portanto, a realidade dos dilemas morais. Mas afinal, o que sustenta esse argumento? Em que ele se baseia? No fato de que o agente tenha certos sentimentos de culpa ou no fato de que tenha certos sentimentos justificados?

É evidente que meros sentimentos de culpa não são suficientes para provar a culpa. Como afirma Foot (2002, p. 41) "é impossível passar da existência do sentimento para a verdade da proposição conceitualmente ligada a ele". E conclui ser incorreto "pensar que a existência de sentimentos de arrependimento possa mostrar qualquer coisa sobre o resquício em casos de conflito moral" (FOOT, 2002, p. 41). Uma reação possível a essa objeção para Statman (1990, p. 197) é distinguir entre sentimentos de culpa genuínos e não-genuinos. Mas qual seria o critério para identificá-los? A princípio, de acordo com Statman (1990, p. 197), sua justificação. Como saber se os sentimentos são justificados? Do fato de que o agente agiu errado e violou um dever moral real. Mas como saber se ele agiu errado? Do fato de que se sente culpado justificadamente. Isso, claramente é uma petição de princípio, que não resolve o problema. Se não se pressupor a culpa do agente, então não há forma de identificar sentimentos de culpa genuínos e o argumento entra em colapso.

Uma saída apontada por Statman (1990, p. 198), bastante engenhosa, é afirmar que talvez a possibilidade de identificar a apropriação dos sentimentos de culpa do agente não dependa epistemologicamente da pressuposição de sua culpa, mas é um tipo de conhecimento direto: não um conhecimento mediado, mas imediato. Dessa forma, o argumento dos sentimentos seria baseado em um tipo de intuicionismo, e os "fatos morais" apreendidos por intuição são a "apropriação" ou a justificação de certos sentimentos. Dessa forma, a justificação dos sentimentos de culpa não seria deduzida, mas "dada", e a única explicação para isso, de acordo com o argumento dos sentimentos seria a culpa do agente. Mas isso, com certeza, não implica na validade do argumento, lembra Statman (1990), que ficaria assim:

a) Os sentimentos de culpa de um agente em um dilema moral são apropriados.

b) A única (ou a melhor) explicação de a é a de que o agente é culpado, e conclui-se.

c) Um dever real é violado em dilemas morais.

d) Logo, dilemas são reais. (STATMAN, 1990, p. 198) 
O argumento dos sentimentos, portanto, é falacioso. Statman (1990, p. 198 ), contudo, aceita a verdade de algumas de suas premissas, em especial a primeira, de que os sentimentos de culpa do agente em dilemas morais são apropriados. O problema é concordar com (b), pois atribuir culpa a alguém, implica que alguém não deveria ter se comportado de certa forma. Mas isso não é o caso em um dilema moral, dado que o agente escolheu a melhor opção. Caso não tivesse agido desse modo, certamente seria culpado. Portanto a explicação de (b) sobre (a) para Statman (1990) não é adequada.

Para Statman (1990, p. 198) há uma maneira melhor de esclarecer (a) do que a explicação de (b). Ele (1990, p. 199) chama tal explicação de

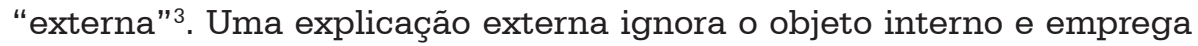
outras considerações para estabelecer os sentimentos. Essa explicação argumenta que embora o agente não seja culpado em um dilema moral, é razoável para ele sentir-se culpado. Quais seriam essas razões externas em favor dos sentimentos de culpa do agente em dilemas morais? Como poderiam esses sentimentos serem racionais, se o agente fez o melhor que podia? Nesse caso não poderia hipoteticamente ser tomado como culpado. Statman (1990, p. 199) oferece duas explicações: 1) baseada no caráter moral; 2) baseada em considerações utilitaristas.

1) As considerações sobre o caráter moral do agente são, para Statman (1990, p. 199), oriundas de concepções aristotélicas. Para Aristóteles, um homem moralmente bom não é aquele que faz boas ações, mas aquele que tem um bom caráter e boa disposição moral: da qual esses atos fluem naturalmente. O ponto que Statman (1990, p. 200) gostaria de ressaltar é que tais disposições de caráter não podem ser ativadas ou desativadas à vontade. Por exemplo, se uma pessoa tem uma forte disposição para não mentir, irá achar difícil mentir. Se mentir sofrerá de sentimentos de culpa, mesmo quando a mentira for justificada. Se alguém insiste que tais sentimentos são irracionais, a resposta provavelmente seria: então um agente moralmente admirável será irracional em determinadas situações, afirma Statman (1990, p. 200).

2) Considere-se agora a perspectiva utilitarista. Uma justificação utilitarista, afirma Statman (1990, p. 200), é baseada nas consequências boas que possam advir dos sentimentos morais. A ideia é que pelo fato dos sentimentos de culpa serem dolorosos, eles ajudariam a prevenir o agente de comportamento imoral no futuro. Por isso, em geral, os sentimentos de culpa seriam importantes para a psicologia moral dos agentes. Evidentemente, ressalta Statman (1990, p. 201), se os

3 Uma explicação "interna", usualmente empregada, ao contrário é dada em termos do objeto interno dos sentimentos relevantes, ou seja, da natureza do fato pelo qual sente-se culpado. 
sentimentos paralisarem o agente ou o deprimirem demais, não seriam justificados. Dessa forma, embora os utilitaristas possam acreditar que há soluções para os dilemas e que, se um agente que tivesse feito o melhor que pôde, ele não poderia ser considerado culpado. Seria desejável que ele se sentisse culpado ainda assim, dados os fundamentos utilitaristas.

Os sentimentos morais se mostrariam, através de tal justificação externa, apropriados e justificados. No entanto, essa justificação não eliminaria o fato de o argumento dos sentimentos ser falacioso, por mais que os sentimentos de culpa do agente sejam apropriados e justificados (Statman, 1990, p. 202).

Além disso, ainda existiria outro elemento em jogo, lembra o autor: os maiores defensores do "argumento dos sentimentos" afirmam que, pelo fato de os sentimentos serem apropriados, o dever superado seria real e não desapareceria como no caso de uma falsa crença para lembrar a comparação de B. Williams entre desejos e crenças. Os oponentes do "argumento dos sentimentos" discordam justamente sobre esse ponto. Contudo, Statman (1990, p. 202) lança a pergunta: sobre o que todos aqueles que discutem os dilemas morais poderiam vir a concordar? Responde em três passos.

Primeiramente, todos poderiam concordar que: a) os sentimentos de culpa do agente em um dilema são a expressão de um caráter moralmente bom e usualmente têm boas consequências; b) situações dilemáticas são situações onde todas as opções envolvem um custo moral capaz de gerar remorso; c) às vezes, fazer a coisa certa em um dilema fere a sensibilidade e o caráter do agente. Torturar terroristas mesmo quando justificado gera, sem dúvida ${ }^{4}$, algum impacto emocional danoso sobre o torturador.

Feito isso, restaria ainda um elemento de desacordo entre aqueles que discutem os dilemas: o status do dever não cumprido (Statman 1990, p. 203). Uns defendem ser real, outros não. Mas o que significaria essa alegada "realidade"? Certamente ela não significaria que se devesse agir de acordo com o dever não cumprido, pois isso implicaria que o outro dever seria errado. Se esse não for o caso, haveria a coisa certa a fazer.

Se a realidade do dever não realizado significar a apropriação de sentimentos de culpa, então isso deveria ser admitido pelos oponentes do argumento dos sentimentos também. Parece que, de acordo com Statman (1990, p. 203), o problema é que o debate não é sobre a apropriação em si do dever não cumprido, mas sobre sua base de explicação. Aqueles que sustentam a "realidade" dos dilemas acreditam que sentimentos

4 Supondo-se que ele tenha alguma sensibilidade moral em relação às suas vítimas. Em geral, parece-nos que eles já são escolhidos por causa da quase total ausência de compaixão com as pessoas a serem torturadas, senão não poderiam realizar suas tarefas. 
de culpa seriam justificados internamente; aqueles que não sustentam acreditam que estes só poderiam ser justificados externamente.

Mas Statman (1990, p. 204) afirma que quando se tenta encontrar a origem dessa discussão, parece que se chega a uma questão ontológica, isto é, se o dever não cumprido existe ou não. Para ele, caso ele exista, a justificação dos sentimentos é interna; caso não, a justificação dos sentimentos de culpa só pode ser externa.

O âmago da questão residiria então (Statman, 1990, p. 205) na vagueza expressa pela pluralidade de termos usados para indicar a realidade do dever superado: "não eliminado de cena", "preserva certa força", etc. Contudo, para o autor caberia perguntar: como poderia tal dever ainda preservar certa força se não seria mais um guia para ação? Por que essa "força" precisaria de uma prova especial como o argumento dos sentimentos? Seria obviamente desnecessário buscar, em casos comuns, razões para agir que foram superadas. (Statman 1990, p. 205).

A partir disso, é possível afirmar que a resposta a esse problema leva inevitavelmente ao debate do realismo moral, como apontam Foot (2002) e Williams (1965). Foot (2002) afirmou que o problema do resquício é importante tanto para os problemas conectados com a "vagueza da realidade das razões" em geral, como para outro problema sério: a realidade "ordinária" das razões não é forte o suficiente para a realidade dos dilemas morais. A realidade dos dilemas precisa de algum conceito "especial" de realidade que é diferente, mas ainda assim inclua a realidade "ordinária".

Nesse ponto, Statman (1990, p. 205) recorre à navalha de Ockham: se o fenômeno dos dilemas pode ser completamente explicado sem pressupor este aspecto ontológico, então este aspecto é supérfluo.

Além disso, Statman (1990, p. 205) lembra que essa discussão sobre a realidade dos dilemas morais pode ser apenas um aspecto da velha discussão sobre o realismo moral, conclusão obtida por Williams (1966) em seu artigo Consistency and Realism. Se esse for o caso, então os dilemas não poderiam mais ser tratados como uma questão filosófica independente da metafísica.

Por isso, Statman desconsidera a discussão sobre a alegada "realidade" dos deveres envolvidos em um dilema e constrói seu modelo partindo das condições básicas para um dilema, sobre as quais não haveria desacordo sobre sua realidade:

1. $P$ deve fazer $A$ e deve fazer $B$ (ou se preferir a terminologia das razões: $P$ tem uma razão para fazer $A$ e uma razão para fazer $B$ ).

2. A e B são incompatíveis.

3. Fazer A e B (separadamente) envolve um alto custo moral (perda). (STATMAN, 1990, p. 206) 
A terceira condição (3) marcaria a diferença entre conflitos morais e meros conflitos triviais. Ou seja, para Statman (1990, p. 206) a condição (3) significaria que apenas quando sério dano (mal) está presente em cada uma das obrigações a serem feitas, que o agente poderá ser considerado como estando em um dilema moral real.

Apenas por isso, os dilemas morais são situações onde é racional e a apropriado sentir culpa e remorso. Isso não é o caso dos meros conflitos morais mais triviais. Por isso que se pode concordar com Statman que essência dos dilemas é o "custo moral (Statman,1990, p. 206).

Para finalizar esta análise do artigo de Statman, cabe algumas observações. Primeiramente. Statman (1990, p. 193) criticou o "argumento dos sentimentos" ao admitir que a apropriação dos sentimentos de culpa do agente em um dilema não implica nem admissão da culpa do agente, nem no reconhecimento da realidade do dever superado (não cumprido). Por isso, para ele este argumento deveria ser rejeitado.

Mas, embora Statman (1990, p. 200) tenha rejeitado o argumento dos sentimentos, ele parece aceitar seus apelos sobre a apropriação dos sentimentos de culpa do agente, pois ele explicou assim a natureza do "custo moral" envolvido em dilemas.

Em segundo lugar, Statman (1990, p. 205) sugere que a discussão sobre a realidade dos dilemas pode não ser frutífera. Seria suficiente para comprovar a existência genuína de dilemas. sem necessidade de apelo a qualquer noção vaga da "realidade do dever não cumprido". A partir disso, defende Statman, seria produtivo focar o debate em algum aspecto "menor" da discussão, como por exemplo: a questão da insolubilidade dos dilemas, a natureza do "custo" moral, a apropriação dos sentimentos de culpa.

Pensa-se que aceitar as conclusões de Statman acima mencionadas e acreditar que seria realmente mais produtivo para a discussão dos dilemas focar em algum dos aspectos "menores" mencionados por ele. Considere-se, por exemplo, o forte apelo que a questão da apropriação dos sentimentos de culpa exerce sobre a discussão dos dilemas.

Este ponto em princípio será escolhido para dar prosseguimento a presente ao nosso. Para tanto, serão utilizadas a partir de agora, as visões de D'arms e Jacobson (2000), que buscam abordar o sentimentalismo moral e os principais problemas que os argumentos sentimentalistas na moralidade precisam enfrentar. Dessa forma, pretende-se discutir a apropriação dos sentimentos de culpa experienciados pelo agente em situações de dilema moral considerando a proposta sentimentalista de D'arms e Jacobson. 


\section{D'arms e Jacobson: sentimento e valor}

A proposta de D'Arms e Jacobson (2000, p. 722) é ousada. Os autores propõem uma espécie de sentimentalismo racional, e criticam duramente os principais autores sentimentalistas contemporâneos. A única justificativa para manterem uma postura sentimentalista a despeito de toda a crítica que realizam é que consideram o apelo sentimental na moralidade a priori extremamente forte. Para os autores, os conceitos da moralidade são "resposta-dependentes" e é praticamente impossível explicá-los sem recorrer a qualquer apelo aos seus sentimentos correlatos. Entretanto, para explicar e justificar estes termos, os autores propõem uma avaliação racional.

Quando se referem aos "termos" da moralidade, D'arms e Jacobson (2000, p. 722) querem se referir aos valores morais. Por acreditarem que a moralidade em si apresenta um "forte apelo" sentimentalista, é que seu principal objetivo é justificar e explicar tal apelo. É fácil enxergar as correlações entre esta ideia de apelo a priori proposta por D'arms e Jacobson e o apelo aos "fatos morais" mencionado anteriormente por Statman acerca dos dilemas. No intuito de tornar tal correlação mais clara, faz-se a uma breve análise do artigo de D'arms e Jacobson em questão.

Para D'Arms e Jacobson (2000, p. 725), o problema principal da tradicional concepção sentimentalista simples é não conseguir explicar a força normativa dos termos morais. Pois, o papel normativo dos termos morais é comandar os sentimentos que são associados a eles.

Os autores afirmam que o sentimentalismo em sua forma simples identifica o julgamento de que uma ação X é errada com a desaprovação de X (e o mesmo raciocínio vale para a sua aprovação). D'arms e Jacobson (2000, p. 724) lembram que duas objeções são feitas a essa visão. A primeira é acusar o sentimentalismo de subjetivismo simples, a teoria de que "X é errado" significaria meramente "Eu desaprovo X". Esta crítica foi dirigida à chamada teoria emotivista da moral que acreditava que os juízos morais não dizem respeito a fatos, além disso as normas e prescrições somente expressam emoções de acordo e desacordo com os atos observados pelo agente. Por isso as prescrições não estariam sujeitas a critérios de verdade e falsidade.

A segunda objeção afirma que se todas as avaliações negativas forem identificadas com atitudes de desaprovação, então a teoria não estará habilitada para distinguir entre os conceitos de errado, mal, feio, vergonhoso, nojento, etc, o que evidentemente é problemático, pois esses conceitos são substancialmente diferentes. Contudo, uma abordagem disposicional de tais conceitos não permite que eles desempenhem esse papel em certos casos. Tais casos, pontuam D'arms e Jacobson (2000, p. 725), 
seriam aqueles onde alguém contesta a opinião corrente de desaprovação ou aprovação de algo. Dessa forma, obter um julgamento minimamente imparcial soa impossível em uma abordagem sentimentalista simples. Por isso, D'Arms e Jacobson (2000, p. 726) apontam que uma possível saída para esse problema seria a de que o proferimento de um julgamento moral não significa simplesmente "ter" um sentimento de aprovação ou desaprovação, mas sim, endossar tal sentimento. E para isso, justificações racionais são inevitavelmente exigidas e devem ser pensadas em conjunto com uma teoria sentimentalista.

Para explicar exatamente a questão que tentam enfrentar, D'arms e Jacobson (2000, p. 729) trazem à tona o "o problema da confluência", comum a todas as teorias sentimentalistas e neosentimentalistas. Mas antes de explicá-lo, vale mostrar aquilo que os autores afirmam ser comum a todas as teorias: a "tese da resposta-dependência" (TRD).

TRD: pensar que $\mathrm{X}$ tem alguma propriedade valorativa $\phi$ é pensar ser apropriado sentir $\mathrm{F}$ em resposta a $\mathrm{X}$.

Através da proposição de TRD, os autores pretendem elucidar uma questão confusa presente em todas as teorias neosentimentalistas, concernente aos julgamentos valorativos: se estes são dotados de valor de verdade ou se é possível atribuir qualquer propriedade aos mesmos, como, por exemplo, "bondade". D'Arms e Jacobson (2000, p. 729) admitem, contudo, que embora TRD possa ser atribuída a todos os neosentimentalistas, a forma como estes irão interpretá-la irá variar.

Por exemplo, os cognitivistas afirmarão: "pensamentos" são os responsáveis por $\mathrm{X}$ ter uma propriedade valorativa $\phi$ e que é apropriado sentir F quando $\mathrm{X}$ ocorre, considerando como "crenças" sobre $\mathrm{X}$ tais sentimentos. Os não-cognitivistas irão tratar tais pensamentos como outra coisa, algum estado mental não-cognitivo. Mas mesmo que se considerem tais diferenças, tanto cognitivistas quanto não-cognitivistas aceitariam que TRD caracteriza apropriadamente a forma pela qual os conceitos valorativos dependem das emoções humanas.

Para D'Arms e Jacobson (2000, p. 730), todos os neosentimentalistas concordam, mesmo que discordem em alguns pontos, no que diz respeito ao fato de que os valores não são propriedades absolutas ou intrínsecas, mas subjetivas e antropocêntricas. Contudo, os autores ressaltam que nenhuma versão do neosentimentalismo conseguiu distinguir suficientemente qual resposta é apropriada e relevante à atribuição de propriedade - se algum X é $\phi$.

Resolver isso seria crucial para o sucesso de qualquer teoria sentimentalista e nenhuma obteve sucesso até o presente momento em estabelecer a verdade de TRD. 
Os autores afirmam que muitas vezes a discussão é estruturada como uma questão acerca da "prioridade" entre a propriedade $\phi$ e a resposta emocional associada a ela. McDowell, teria assumido, que, dada a base subjetiva dos valores nas respostas emocionais humanas, falar da verdade de julgamentos valorativos deveria ser alcançado, não meramente "suposto" ou "dado" (D'Arms e Jacobson, 2000, p. 730) ${ }^{5}$

Já Wiggins alcançar a noção de verdade, por exemplo, significaria argumentar "que todos nós temos à nossa disposição um conjunto de razões para o pensamento ético que é suficientemente rico e substancial para diferenciar racionalmente comprometimentos induzidos em posturas éticas de alterações induzidas por mera manipulação (D'Arms e Jacobson, 2000, p. 730) 6 .

D'arms e Jacobson (2000, p. 730) afirmam que o raciocínio de Wiggins levaria a crer que temos uma habilidade para priorizar a nossa sensibilidade de acordo com o que são as melhores razões para suas respostas emocionais do que outras. O problema seria que tal argumento daria a entender que tais razões já viriam impregnadas de comprometimentos éticos, o que para D'Arms e Jacobson (2000, p. 730) seria bastante problemático.

Para os eles, também McDowell (1997, p. 208) não responde à questão crucial do problema da confluência: se restringirmos nossa atenção às respostas morais, nem todas as razões contra e a favor das mesmas seriam pertinentes para dizer se elas seriam apropriadas em algum sentido relevante. D'Arms e Jacobson (2000, p. 730) afirmam, portanto, que McDowell não teria feito progresso algum na tentativa de estabelecer um sentido relevante para resposta "apropriada" em TRD. Ainda, até que seja distinguida uma noção relevante de "apropriação", nenhum filósofo teria alcançado uma noção "merecida" de verdade ou mesmo um conhecimento ou objetividade acerca dos julgamentos valorativos.

Wiggins (1997, p. 198) sugeriu que há uma evolução social das propriedades valorativas e suas respostas emocionais humanas, porque a matéria dos sentimentos depende também da história das práticas valorativas das pessoas que os sentem. A questão é que, embora os padrões culturais exerçam grande influência na maneira como as pessoas se sentem, existem aqueles membros que os rejeitam. Wiggins (1997, p. 198) pensa assim que para que um conceito valorativo exerça sua função no discurso normativo, ele deve ser "essencialmente contestável".

Contudo, a ideia de "essencialmente contestável" mostra que nada responde adequadamente às questões anteriores acerca da apropriação

5 Para o texto de McDowell ver (1997, p. 207).

6 Para o texto de Wiggins, (1997, p. 197). 
das respostas emocionais, ao invés disso, chega até a sugerir que a função de julgamentos valorativos requer que sua aplicação permaneça aberta a revisão pela comunidade de pessoas de uma cultura.

Dessa forma, será que nem Wiggins (1997), nem McDowell (1997) teriam respondido adequadamente ao desafio de TRD como questionam D'Arms e Jacobson (2000, p. 738)? O problema essencial, que todos parecem deixar escapar, afirmam D'Arms e Jacobson (2000, p. 738), é como circunscrever o sentido de "apropriado" de tal forma que o dictum "pensar que X é $\phi$ é pensar que F é uma resposta apropriada a X", seja verdadeiro.

Até que isso seja feito, falar sobre a verdade ou objetividade dos julgamentos valorativos ou como tais julgamentos seriam capazes de alguma espécie de conhecimento, parece irreal.

Gibbard (1990, p. 6), por seu turno, utiliza o termo "racional" como a expressão linguística adequada para expressar endosso. Para o ele, dizer que algo é racional é o mesmo que endossá-lo. O autor também afirma que algo é racional quando faz sentido pensá-lo e aceitar as normas que o permitem.

D'Arms e Jacobson (2000) afirmam que para Gibbard (1990, p. 56), as ações (crenças, desejos ou emoções) que alguém endossa como racionais são as ações que este alguém realizará (ou as crenças, desejos ou emoções que irá adotar), independentemente de estarem sob seu controle voluntário. Pois, lembram os autores, podem acontecer ações acráticas, onde a pessoa endossa certas normas, mas age contrariamente a elas, mostrando que embora as considere racionais, estas não estão voluntariamente sob seu controle às vezes.

Para Gibbard (1990, p. 51), contudo, as normas podem ser entendidas racionalmente e têm força motivadora intrínseca, ligada às emoções. A partir daí, Gibbard (1990, p. 56) propõe uma teoria do julgamento moral derivada de uma abordagem expressivo-normativa da racionalidade.

Na teoria moral de Gibbard (1990, p. 51), pensar uma ação como errada, é o mesmo que pensar ser racional para o agente sentir culpa e as outras pessoas se ressentirem do agente por ter agido da forma como agiu.

Entretanto, perguntam D'Arms e Jacobson (2000, p. 739), como estabelecer o que é uma "emoção racional"? Gibbard (1990, p. 36) responderia que a noção de racionalidade acerca de uma emoção seria a mesma que utilizamos como parâmetro para avaliar uma crença: a de ela estar justificada. Para Gibbard (1990, p. 36), essa é uma evidência autosuficiente e pode ser aplicada para explicar a racionalidade das emoções.

D'Arms e Jacobson (2000, p. 740) porém, afirmam que restariam ainda dois problemas cruciais a serem resolvidos na teoria de Gibbard (1990). 
O primeiro deles é que, embora Gibbard tenha mostrado uma maneira de restringir as considerações relevantes para a atribuição de propriedade $\phi$, ou seja, a identificação de "julgamentos da racionalidade" com "flavorless endorsement" torna o ideia anterior inviável para sua teoria.

O segundo problema diz respeito ao fato de que, embora a noção de justificação das emoções esteja no caminho correto, ela vai em uma via que a impediria se capturar o sentido de "apropriação" requerido por TRD. Por fim D'Arms e Jacobson (2000, p. 745) afirmam que a ideia de Gibbard de que julgamentos sobre o errado podem ser entendidos em termos de culpa ou ressentimentos justificados, não ofereceria qualquer explicação para a alegada conexão entre valor e sentimento; deixando a questão novamente em aberto.

D'arms e Jacobson (2000, p. 747) mostram, portanto, que o problema de TRD ainda teria que ser solucionado. Eles reafirmam a ideia de que isso só seria possível através de um "sentimentalismo racional", porque, esta seria a única forma de oferecer critérios capazes de estabelecer e restringir adequadamente a alegada "apropriação" das respostas sentimentais em relação às normas morais.

\section{Dilemas morais e apropriação dos sentimentos em sua abordagem}

Nesse momento, o objetivo é traçar as correlações entre aquilo que foi exposto do artigo de Statman (1990), o artigo de D'arms e Jacobson (2000) e as colocações preliminares realizadas por Williams (1965) e que deram origem a presente discussão.

Primeiramente, é preciso ser dito, que esse trabalho parte do pressuposto de que há evidência de elementos emocionais que influenciam a moralidade tais como a culpa, a vergonha, o remorso, o ressentimento, a compaixão, a indignação.

Como foi visto, esse é um problema recorrente na história da filosofia ${ }^{7}$. D'arms e Jacobson (2000) defendem, no entanto, uma proposta diferenciada - uma espécie de sentimentalismo racional, criticando duramente o sentimentalismo moral "simples", por acreditarem que a discussão não possa ser dividida em pólos: racionalismo versus sentimentalismo. Essa discussão traz à tona o velho problema da conexão entre os valores morais, os sentimentos e o papel da razão nesse processo. Diversas correntes éticas como alguns utilitaristas e Kant optaram por

Não se pode aqui recorrer a toda essa trajetória. Os séculos XVII e XVIII foram extremamente fecundos neste debate basta lembrar Adam Smith, R, Descartes, J.-J Rousseau, David Hume, B. Spinoza somente para mencionar alguns mais conhecidos. A discussão contemporânea é a que nos interessa aqui. 
um viés principialista e racional, e rejeitando o papel relevante dos sentimentos, emoções ou paixões, na moralidade humana.

O enfoque deste trabalho associou procurou também relacionar o tema mencionado aos dilemas morais, porque nos últimos quarenta anos, como mencionou Statman (1990) visões sentimentalistas e neosentimentalistas têm tido um papel relevante no debate acerca da existência dos dilemas morais e do modo como agentes morais enfrentam tais situações e decisões morais difíceis.

Mas por que, afinal, a discussão gira sobre esse ponto elementar dos sentimentos morais? A experiência de um dilema moral seja ele trágico ou não, parece uma experiência ordinária na vida moral de qualquer ser humano. Pode não ser exatamente "comum" ou cotidiana, mas ordinariamente, é difícil conhecer alguém que não tenha passado por uma decisão moral difícil. Discutir sobre sua existência é, no mínimo, intrigante.

A questão pensa-se, é que a existência dos dilemas entra em discussão porque as teorias morais precisam enfrentar-se ao enfrentá-los. Ao se admitir a genuinidade de um dilema moral, está se afirmando que, por vezes, a moralidade emite conselhos contraditórios ou então conselho algum. Teorias de cunho estritamente racionalista precisam apontar a solução para estes casos e, de fato, apontam. Mas porque mostram a solução, também derivam daí a ideia de que o dilema era, por isso, meramente aparente, e os sentimentos de culpa do agente devem ser desconsiderados ou justificados apenas externamente. Mas este é um ônus desnecessário caso se considere uma abordagem sentimentalista dos dilemas.

A tendência a negar a existência dos dilemas e por isso desconsiderar completamente os sentimentos de culpa envolvidos, revela talvez uma necessidade de tais teorias de preservarem a estabilidade de seus princípios e a própria estabilidade da razão humana. Mas, a um preço caro demais: desconsiderar completamente o papel das emoções no processo da moralidade como um todo e desprezar os sentimentos de culpa e arrependimento (muitas vezes apropriados) experienciados em dilemas morais pelo agente.

Dessa forma, o que se gostaria de deixar claro nesse trabalho é o seguinte: os problemas clássicos apontados por D'arms e Jacobson (2000) nada mais são do que os mesmos problemas apontados por Statman (1990) e por Williams (1965) quando abordam os dilemas morais. Mais do que isso: discutir acerca da realidade de dilemas é desviar o foco de atenção do que realmente interessa, ou seja, a apropriação e justificação dos sentimentos de culpa vivenciados pelo agente no momento da escolha e a noção de custo moral. Isto abre caminho para 
uma abordagem sentimental acerca da resolução de dilemas morais. Os desafios teóricos que o sentimentalismo enfrenta já foram colocados, e serão, evidentemente, também os desafios de uma concepção que prefere considerar os sentimentos de culpa do agente como apropriados em um dilema moral.

O que fundamenta tal apropriação de sentimentos em dilemas? Por que focar-se nessa questão? Porque como foi dito anteriormente, isso tem a ver com um apelo aos fatos morais, que têm sido confirmados por pesquisas recentemente mencionadas por autores como Prinz (2012), Churchland (2011), entre outros, que buscam explicações científicas para os valores e os comportamento morais.

E o que as pesquisas destes autores têm revelado? Que, por exemplo, D. Hume poderia estar certo na sua visão acerca da moralidade. Mas esta temática merece e deve ser abordada em um trabalho em separado. Este artigo buscou apenas concentrar-se em alguns aspectos teóricos da presente discussão, pois, iniciar uma análise mais prática, demandaria a incursão pelo mencionado universo das pesquisas empíricas sobre as situações morais dilemáticas. algo que certamente virá a ser realizado em uma próxima ocasião.

\section{Referências}

BRINK, D, O. Moral Dilemmas and its Structure. The Philosophical Review, 2 (1994), p. 215-247.

CHURCHLAND, P. Braintrust. What neuroscience tells about morality. Princeton: Princeton University Press, 2011.

D'ARMS J. JACOBSON, D. Sentiment and Value. Ethics, 110, 4 (2000), p. 722-748. <http://dx.doi.org/10.1086/233371>.

FOOT, P. Moral Dilemmas Revisited. In: Moral Dilemmas. Oxford: Oxford University Press, p. 175-187, 2002. <http://dx.doi.org/10.1093/019925284X.001.0001>. GIBBARD, A. Wise choices, Apt Feelings. Cambridge: Harvard University Press, 1990. HUME, D. Enquiry concerning Human Understanding and concerning the Principles of Morals. Oxford: Oxford Clarendon Press, 1975. <http://dx.doi.org/10.1093/ actrade/9780198245353.book.1>.

McCDOWELL, J. Values and Secondary Qualities. In: DARWALL, S.; GIBBARD, A.; RAILTON, P. (Ed.). Moral Discourse and Practice. Oxford: Oxford University Press, 1997, p. 201-214.

PRINZ, J. Beyond the Human Nature: how culture and experience shape the human mind. W. W. Norton \& Company, 2012.

STATMAN, D. The Debate over the So-called Reality of Moral Dilemmas. Philosophical Papers, XIX, 3 (1990), p. 191-211. <http://dx.doi.org/10.1080/05568649009506337>.

WIGGINS, D. A Sensible Subejectivism? In: DARWALL, S.; GIBBARD, A.; RAILTON, P. (Ed.). Moral Discourse and Practice. Oxford: Oxford University Press, 1997, p. 227-244. 
WILLIAMS, B. Ethical Consistency. Proceedings of the Aristotelian Society, 39, (1965), p. 103-124.

WILLIAMS, B. Consistency and Realism. Proceedings of the Aristotelian Society, 40 (1966), p. 1-22, 1966.

\section{Endereço postal:}

Universidade Federal de Santa Maria

Centro de Ciências Sociais e Humanas

Programa de Pós-graduação em Filosofia

Av. Roraima, 1000 - Prédio 74-A, sala 2308 - Campus Bairro Camobi

Santa Maria, RS, Brasil

Data de recebimento: 23/04/2014

Data de aceite: 15/01/2015 